Current Issues in Middle Level Education

Volume $25 \mid$ Issue 2

Article 3

2020

\title{
Uncharted WATERS: Sustaining a Meaningful Student Teaching Experience Amidst a Global Pandemic via an Online STEM Curriculum
}

\author{
Nanette I. Marcum-Dietrich \\ Millersville University of Pennsylvania, ndietrich@millersville.edu \\ Cindy Stunkard \\ Kutztown University of Pennsylvania, Stunkard@kutztown.edu \\ Zachary Krauss \\ Millersville University of Pennsylvania, zjkrauss@millersville.edu
}

Steve Kerlin

Stroud Water Research Center, skerlin@stroudcenter.org

Follow this and additional works at: https://digitalcommons.georgiasouthern.edu/cimle

Part of the Curriculum and Instruction Commons, Educational Technology Commons, Junior High, Intermediate,

Middle School Education and Teaching Commons, Online and Distance Education Commons, and the Secondary Education Commons

\section{Recommended Citation}

Marcum-Dietrich, Nanette I.; Stunkard, Cindy; Krauss, Zachary; and Kerlin, Steve (2020) "Uncharted WATERS: Sustaining a Meaningful Student Teaching Experience Amidst a Global Pandemic via an Online STEM Curriculum," Current Issues in Middle Level Education: Vol. 25 : Iss. 2 , Article 3.

DOI: $10.20429 /$ cimle.2021.250203

Available at: https://digitalcommons.georgiasouthern.edu/cimle/vol25/iss $2 / 3$

This research is brought to you for free and open access by the Journals at Digital Commons@Georgia Southern. It has been accepted for inclusion in Current Issues in Middle Level Education by an authorized administrator of Digital Commons@Georgia Southern. For more information, please contact digitalcommons@georgiasouthern.edu. 


\section{Uncharted WATERS: Sustaining a Meaningful Student Teaching Experience Amidst a Global Pandemic via an Online STEM Curriculum}

\section{Cover Page Footnote}

This material is based upon work supported by the National Science Foundation under Grant No. DRL-1850060 Any opinions, findings, and conclusions or recommendations expressed in this material are those of the author(s) and do not necessarily reflect the views of the National Science Foundation.

This research is available in Current Issues in Middle Level Education: https://digitalcommons.georgiasouthern.edu/cimle/vol25/iss2/3 
Marcum-Dietrich et al.: Uncharted WATERS

\title{
Uncharted WATERS: Sustaining a Meaningful Student Teaching Experience amidst a Global Pandemic via an Online STEM Curriculum
}

\author{
Nanette I. Marcum-Dietrich \\ Millersville University of Pennsylvania \\ Cindy Stunkard \\ Kutztown University of Pennsylvania \\ Zachary Krauss \\ Millersville University of Pennsylvania \\ Steve Kerlin \\ Stroud Water Research Center
}

\begin{abstract}
Field experience is the culminating experience for pre-service teacher training. As COVID-19 closed schools across the country, pre-service teachers' field experiences were disrupted. This case study examines how a student teacher, a team of mentor teachers, and a university supervisor at a regional public university adapted to remote learning. The findings suggest that there were gains and losses in terms of the pre-service teachers' ability to develop essential skills; classroom management skills suffered while formative assessment practices, innovative lesson delivery, and reflection on instruction were enhanced. The transition to remote learning also caused the way student teachers' skills were valued, as well as the effectiveness of their teaching, to change. How future teachers are prepared will need to be altered. Going forward, all teachers will need the skills to reach students in a variety of environments including face-to-face, remote, and hybrid models.
\end{abstract}

\section{Introduction}

When the COVID-19 pandemic hit in the Spring of 2020, the world's education system was turned on its head. Classrooms were shuttered as learning moved online. Many teaching methods that reflected research-based best practices in a traditional classroom setting did not apply or translate to remote learning. K-12 education. This required immediate and profound rethinking in_order to respond to the crisis. During this crisis, even the most veteran teacher became a novice as all teachers had to adapt to new pedagogical approaches and modes of instruction, for which they had not been trained. Colleges of education were also faced with a crisis, how to prepare teachers during these unprecedented times. They needed to provide future teachers with meaningful field experiences when in-person classrooms were abruptly transformed into remote online learning, led by teachers with little or no training in online pedagogy. The traditional model of pairing a pre-service teacher with a mentor teacher in a physical classroom was no longer possible. When practices in K-12 schools change, colleges of education must adapt to these new methods as well (Dever, 2020). Rather than delaying pre- 
service teachers' education, many colleges of education pivoted and opted to have pre-service teachers continue with their field experiences by joining veteran teachers on this unprecedented journey. Together mentor teachers and pre-service teachers set out to define what teaching in an age of social isolation and remote learning should look like.

The team of teachers, including the student teacher, were part of an NSF curriculum project called WATERS: Watershed Awareness using Technology and Environmental Research for Sustainability. The 10-lesson WATERS curriculum unit had existing online, classroom, and field-based components with the lessons organized and accessed in an online learning portal. Teachers were motivated by the challenge of finding ways to adapt the curriculum, including the outdoor elements and hands-on activities, to an online delivery format, while also supporting the growth of the student teacher.

\section{Background Information}

Having more than 150 years of experience training teachers, a regional public university in the Mid-Atlantic region of the United States found itself unprepared for the upheaval that transpired in the Spring of 2020. This historic College of Education prides itself on its ability to respond to the changing needs of the profession. For example, in 2006, the institution radically restructured its program for secondary teacher preparation by adopting a professional development school (PDS) model where field experience was elevated as the keystone of the program. In the PDS model, during their final year of undergraduate education, pre-service teachers participate in a year-long internship program that complements their coursework. Being nimble and responsive to the needs of the profession is a valued trait of the institution, but the rapid spread of COVID-19 left the institution scrambling to adapt. Using a case study methodology (Creswell, 2013), the researchers sought to understand how the COVID-19 outbreak impacted pre-service teachers' field experience at this institution. The researchers interviewed the field experience coordinator, a university supervisor, a pre-service teacher ${ }_{2}$ and his mentor teacher. The interviews were conducted via ZOOM video conferencing software and transcribed. The data was reviewed in the crafting of the resulting narrative that described their experiences in the Spring of 2020.

\section{Things Change - "Hey, we're not coming in on Monday."}

Throughout the crisis, we are reminded that change is possible and giving up is not an option! The immediacy of this crisis caused by the spread of COVID-19 cannot be understated. For one pre-service teacher who was completing his field experience at a local middle school, nothing could have foreshadowed the profound impact a simple text from his cooperating teacher would have on his education. On a Friday afternoon in March of 2020, his mentor teacher sent a text, "Hey, we're not coming in on Monday". Little did they both know: teachers and students would not enter the middle school building again for the remainder of the academic year. Initially teachers were told the school would close for a week to deep clean the building. As the scope of the situation became evident, the school made the difficult decision to transition to remote online learning for the remainder of the school year.

Teachers are adaptable, every day we navigate the unexpected. The internet is down, so we make 30 paper copies of the online article we want our students to read. The cart of laptops we reserved weeks in advance is not returned, so we gracefully substitute a different activity. During the COVID_19 crisis, teachers' adaptability was put to the test. After the abrupt closure, most schools moved instruction online without a detailed implementation plan or adequate 
professional development. For the middle school in this case study, the one-week closure extended to two weeks as administrators assessed the situation. At the university, the field experience coordinator, tasked with guiding the institution's response, took a measured response to the crisis. She said, "Let's not be hasty. Let's see what is being asked of our mentors (teachers)."

\section{Learning Together}

The middle school eventually made the difficult decision to close its physical doors and to move all instruction online. Without professional development and using only the available technology, the teachers relied on each other. The middle school's website states that it "utilizes a team approach in which teachers and students are divided into 'learning community' teams to facilitate exploration of subjects and cross-curricular understanding". The school's team structure became the teachers' greatest asset in responding to the challenge; because, while it was unprecedented, teachers were accustomed to working together. Recent research has shown that "an existing collegial relationship is a great starting point to promote interactions and trust among members" of an online-teaching team during the pandemic (Ferdig et al., 2020). Prior to the closure, the middle school functioned using grade-level interdisciplinary teams. Tasked with planning subject-specific online instruction, the team structure changed. Instead of working in interdisciplinary teams, teachers worked in subject-specific teams to create eight weeks of online, asynchronous instruction for their students.

In this new online environment, the veteran teachers were transformed into novice teachers. The mentor teacher explained, "I'm literally a first-year teacher all over again!" The pre-service teacher's role changed from being the apprentice working side by side with a mentor teacher to being a fully contributing member of the subject-specific team. In this example, members of the team consisted of three practicing science teachers (two teachers with 25 plus years of experience and one teacher with less than three years of experience), the subject area supervisor, and the pre-service teacher.

Integrating the pre-service teacher into the team of science teachers took intentional planning. The traditional hierarchy of mentor teacher and student teacher was disrupted. Initially, the cooperating teacher needed to figure out what he was doing and how the team of teachers would function before integrating the student teacher. The cooperating teacher explained, "I felt bad for [student teacher] because he was in a standby pattern." He kept emailing asking, "do you know what we're doing?' I said, 'Honestly, I have no idea what we're doing."' Once they met as a team and had a plan, the mentor teacher decided that, while the student-teaching experience would be different, it would still be a valuable learning experience. They proceeded by fully integrating the pre-service student teacher into the subject-specific team.

\section{Team Teaching}

Tasked with creating online learning opportunities for their students, the team of teachers combined their students into one large online class of 308 seventh grade students. As a team, they were given leeway to design the online curriculum. Looking at the science topics left to cover, the team chose to teach about watersheds. Fortunately, the teachers were part of an NSF grant-funded curriculum project called Watershed Awareness using Technology and Environmental Research for Sustainability (WATERS). Prior to the outbreak of COVID-19 the teachers received extensive professional development on this unit of instruction that was intended to be delivered in a face-to-face format, with some classroom, outdoor, and online 
learning activities. The teachers reported that using an existing curriculum afforded them the ability to focus, not solely on curriculum construction, but on adaptation to online delivery and supporting the needs of their online learners.

When the group of teachers met, they discovered that each teacher had individual strengths including technology skills, connecting with students, encouraging involvement, and organizational skills to keep the team on task. Supporting each other, the teachers, including the pre-service teacher, divided the outdoor and hands-on components. Each teacher took the lead in adapting one specific outdoor and hands-on component for asynchronous online delivery, and the student teacher supported them by creating supplemental instructional videos. By working together, the teachers were able to support each other and to share the work required to adapt the WATERS curriculum to a completely online format that met the needs of the students. According to the mentor teacher, the student teacher "just plugged in, everywhere you know he was the one who, if I said, hey, we need this to happen, he goes, 'I'll do it."'

The WATERS curriculum, which the team chose to adapt for online delivery, is designed using the Meaningful Watershed Education Experience (MWEE) curricular framework (NOAA, 2017). One of the Essential Elements of a MWEE is "outdoor field experiences." The outdoor field experiences proved to be the most difficult component to implement during this time of home-isolation amidst a global pandemic. Thankfully, the teachers brainstormed a workable alternative. In one of the outdoor field experiences, students traditionally take water samples at their local stream and perform chemical testing to analyze the health of the stream as a class; this could not be done in its intended way. Rather than having students travel to the stream, a teacher on the team video recorded herself at the stream taking the water samples step-by-step and posted it as a video for the students to analyze. The students were able to compare the results of the chemical reactions in each sample to the comparator card to determine the reading and record the data on their own computers, despite being unable to perform the task themselves. For another activity, students were to sample the stream's macroinvertebrates as a bioassessment of stream health. This lesson was also modified by the team using videos, images, and other online resources. Tackling these instructional challenges would have been overwhelming if not for the team structure. Students indicated that the simulated activities helped them understand the watershed's health despite not physically completing the outdoor components.

\section{Affordances and Hinderances to the Pre-Service Teacher's Growth}

In this case study, the student teacher and mentor teacher each indicated that there were gains and losses in terms of the student teaching experience. The student teacher said “...classroom management was one of the things I struggled with when I was teaching and planning my first lesson... when I was ready for my next unit, COVID hit and I didn't have the opportunity to practice my classroom management." The cooperating teacher echoed this by saying "...we had this plan figured out - how we were going to work on things like classroom management with his in-person teaching. He got short changed a little bit. We didn't have a chance to flesh those out." Virtual teaching does not require the same classroom management skills that are essential in face-to-face teaching, so the student teacher was not afforded the opportunity to refine this skill; he will graduate without showing proficiency in this area.

In this case study, the middle school adopted an asynchronous model for its virtual instruction. With this model, all instruction was prepared in advance and accessed by students via the learning management system in the form of short instructional videos, readings, online 
simulations, etc. As part of his field-experience, the student teacher was tasked with preparing short instructional videos that included demonstrations about watersheds with students joining in using household items. As a digital native (Prensky, 2001), having more digital and technological skills than the veteran teachers on the team, the student teacher leveraged skills that may not have been as valued in a traditional face-to-face model of student teaching. In this scenario, the student teacher possessed the skills needed to overcome the technical hurdles of preparing video lessons that many veteran teachers contended with in the Spring of 2020.

The need to create instructional videos for students to access in this asynchronous virtual environment resulted in some unanticipated benefits to the student teacher's professional preparation. He explained how this mode of lesson delivery encouraged him to engage in a process of reflection and revision: “...being virtual, I was able to record myself which allowed personal reflection on my teaching and allowed me to listen to each lesson, review it, correct my mistakes, and improve it before showing it to the students. Virtual learning allowed for dress rehearsals." Student teachers are routinely encouraged to record and to reflect on their teaching, but the act of preparing pre-recorded mini lessons made this a daily practice. A practice that was enhanced by the ability to refine and re-teach the material until he was satisfied with the quality of his teaching. This is something that is rarely possible in the traditional face-to-face setting where every day is a performance as new instruction is delivered in "real-time" and where "dress rehearsal" is not possible.

When asked about the dynamics of student teaching and mentoring in this COVID-19 imposed virtual environment, the university supervisor confirmed what we heard from the student teacher and mentor teacher, saying that many of the student teachers have a great aptitude for technology but less so for classroom management (while the mentor teachers' skillsets are often flipped), allowing for a role reversal at some points during online learning. As a result of the transition to online learning, student teachers were given expanded access to the school's technology resources and infrastructure; including credentials to access the schools' online learning management systems which had previously been restricted. With this expanded access to resources, the student teachers were able to gain enhanced experience in instructional technology integration.

In this virtual learning environment, teachers prepared online instruction; students engaged with the material and submitted written work online. Grades were recorded in the online gradebook; but formative feedback was limited. The mentor teacher identified the deficiency in the quality and quantity of the formative feedback they were providing their students in this new virtual environment. He instructed the student teacher to take the lead on reviewing students' submissions and providing weekly online feedback to students. The student teacher explained that his job was, "...helping give feedback to the kids, seeing what they understood, what they didn't understand then, but could be worded differently after each activity or unit. I wrote up a reflection about what the kids did right, what they did wrong, and how it can be improved." Targeted, specific feedback is a skill that is underdeveloped in most novice teachers (Hattie \& Timperley, 2007). Providing feedback to students online allowed for more in-depth reflection on student performance and increased this skill in the student teacher.

Both the mentor teacher and university supervisor used a standardized evaluation tool to evaluate the student teacher, in this case, the Danielson Framework for Teaching (FFT). The FFT assesses student performance in four domains: planning \& preparation, classroom environment, instruction, and professional responsibilities. Due to the shift to virtual learning, some of the 
items on the FFT could not be measured in a traditional sense. The evaluation tools needed to adapt to the current context. The FFT has since been updated to reflect the priorities, actions, and strategies that align to proficient and distinguished professional practice in remote learning during this time of crisis (Danielson Group, 2020).

\section{Going Forward - Lasting Changes}

How future teachers are prepared will need to be altered. Going forward, all teachers will need the skills to reach students in a variety of environments including face-to-face, remotely (both asynchronously and synchronously), as well as a hybrid blended model of teaching and learning. The mentor teacher said,

As I look ahead to my, you know, the next 10 years of teaching before I retire. I think it's gonna be different than the last 20. I think there's going to be more of this [remote teaching] ... I think there's always going to be some aspect of kids not being in school with us and we're gonna have to address that. Prior to this year, it was not addressed in any way in student teaching. The focus was always what's going on in the classroom. And as I said as I see things change; there's going to be a lot more focus on digital teaching. I think he got a student teaching experience unlike any other...

Colleges of education are going to have to adapt to this new reality by expanding field experience opportunities to include teaching in different modalities incorporating a variety of technologies.

The Spring of 2020 put novice and veteran teachers to the test. The mentor teacher said,

We are flexing teaching muscles I didn't know existed...it was a completely different experience than we planned for...these were things that I personally had never done...we had this game plan for a couple of weeks [next unit] and the rug was pulled out and we were both learning new skills. In some cases, he [student teacher] was teaching me...to some extent we switched roles. It was an interesting time for sure.

Both colleges of education and practicing teachers will need to be responsive to the changing context of teaching and learning. Teachers will continue to be flexible and nimble when addressing changes. While universities may take some time to adjust to the "new normal" of teaching, each will need to change the way preparing teachers is done.

\section{Conclusion}

While student teachers lost valuable experience working on their classroom management skills, they gained new experiences teaching in an online environment, and the university supervisor believes that this experience teaching online is what helped May 2020 graduates secure teaching jobs during the ongoing pandemic. In an ideal world, the university supervisor hopes "we get back what we lost and don't lose what we gained". The university supervisor's ending wish sums up the past eight months well; we have all acquired new skills but at the expense of many missed opportunities.

As researchers and practitioners, we expect that both in-class and online teaching skills will be of great value as a blended learning environment has and will become more common. With this expansion of how instruction is delivered, colleges of education must enact changes to their existing preparation program to reflect the proficiencies and skills educators need to 
effectively educate students in a diversity of formats. Future teachers need to be prepared to teach remotely and face-to-face. Conversely, university supervisors must learn new skills to observe and provide feedback to student teachers based on formats other than face-to-face. In response, the profession must consider new evaluation tools to better assess teaching in online and blended learning environments, as the university in this study has done for its pre-service teaching program. Mentor teachers must emphasize skills not essential in traditional face-to-face teaching - such as the ability to create asynchronous instructional units, the ability to produce short instructional videos, and effective strategies to provide online formative feedback to students - while also providing pre-service teachers with the opportunity to develop proficiencies in skills essential to face to face teaching including classroom management. In future student teaching situations, all skills will need equal footing. Ideally, returning to a traditional face-toface teaching environment is preferred; however, returning to that environment will also need to incorporate and build on the lessons learned during this time of crisis.

While we hope that things return to normal sooner rather than later, we have entered a new era in education with a new breadth of knowledge and new abilities. We await the day that teachers and students end up back in the classroom on a regular basis; but, even when they do, online learning will not disappear. We have seen that having prepared online lessons can facilitate an abrupt shift to remote learning; the innovative teachers in this case study have shown that even the most hands-on lessons can be successful in an online setting.

\section{References}

Creswell, J. W. (2013). Qualitative inquiry and research design: Choosing among five approaches. Sage.

Danielson Group. (2020). Framework for remote learning. Retrieved November 20, 2020, https:/www.k12.wa.us/sites/default/files/public/tpep/frameworks/danielson/The\%20Fra mework $\% 20$ for $\% 20$ Remote $\% 20$ Teaching\%20doc.pdf

Dever, R. (2020). Middle level faculty and change. Current Issues in Middle Level Education, 25(1). doi:10.20429/cimle.2020.250103

Ferdig, R., \& Mouza, C., Hartshorne, R., \& Baumgartner, E., \& Kaplan-Rakowski, R. (2020). Teaching, technology, and teacher education during the COVID-19 pandemic: Stories from the field. Association for the Advancement of Computing in Education (AACE).

Hattie, J. \& Timperley, H. (2007). The power of feedback. Review of Educational Research, (77) $1,81-112$.

NOAA Meaningful Watershed Educational Experience: National Oceanic and Atmospheric Administration. (2017). Retrieved July 16, 2020, from https://www.noaa.gov/education/explainers/noaa-meaningful-watershededucational-experience

Prensky, M. (2001). Digital natives, digital immigrants, Part 1. On the Horizon 9(5), 1-6. 